\title{
Towards a complete species tree of Nymphaea: shedding further light on subg. Brachyceras and its relationships to the Australian water-lilies
}

\section{Thomas Borsch ${ }^{1}$, Cornelia Löhne ${ }^{1}$, Mame Samba Mbaye² and John Wiersema ${ }^{3}$}

\author{
${ }^{1}$ Botanischer Garten und Botanisches Museum Berlin-Dahlem und Institut für Biologie, Freie \\ Universität Berlin, Königin Luise-Straße 6-8, 14195 Berlin, Germany \\ ${ }^{2}$ Département de Biologie Végétale, Université Cheikh Anta Diop de Dakar, BP5005, Dakar-Fann, \\ Sénégal \\ ${ }^{3}$ Gambrills, MD 21054, USA \\ Author for correspondence: t.borsch@bgbm.org
}

\begin{abstract}
The water-lily genus Nymphaea exhibits a worldwide distribution with an estimated number of more than 50 extant species. Recent phylogenetic analyses resolved three major lineages, a subg. Brachyceras-subg. Anecphya clade, also including Nymphaea ondinea, a subg. Hydrocallis-subg. Lotos clade, and the temperate subg. Nymphaea as a third clade. This study extends the taxon sampling for Brachyceras, previously the least understood subgenus. Maximum Parsimony and Bayesian analysis of nrITS sequence data depict a monophyletic subg. Brachyceras-clade and show a New World clade to be nested within African taxa. Plastid $\operatorname{trn} \mathrm{T}$-trnF sequence data are less conclusive. A middle Miocene origin is inferred for the New World Brachyceras lineage that must have dispersed out of Africa either via a Beringian migrational route or through immediate long distance dispersal. Within subg. Brachyceras, the West African individuals of Nymphaea guineensis form a distinct clade in both nuclear and plastid trees to which the Madagascan Nymphaea minuta is sister. Central and East African Brachyceras species appear well separated, suggesting a separating effect of the Dahomey gap to the evolution of these species. ITS sequences are more powerful in identifying Nymphaea species than $\operatorname{trn} \mathrm{T}-\operatorname{trn} \mathrm{F}$ sequences. Nevertheless, about $15 \%$ of the known species remain to be sampled for a complete molecular tree of water-lilies. This also requires sampling of multiple populations in order to discover entities with a common evolutionary history and distinct molecular and morphological characters.
\end{abstract}

\section{Introduction}

Among all genera of the water-lily clade (Nymphaeales), Nymphaea is the most diverse lineage with more than 50 species. Recent molecular phylogenetic analyses have shown several lineages that represent species radiations on certain continents (Borsch et al. 2007, 2008; Löhne et al. 2007). A lineage comprising all temperate species in Eurasia and North America gains high support from both DNA and morphology, and 
corresponds to subg. Nymphaea. Two lineages with night bloomers appear vicariant for the New and Old World Tropics, respectively. The monophyletic subg. Hydrocallis occurs in Mexico, the Caribbean, Central and South America (Wiersema 1987, Löhne et al. 2008b) whereas subg. Lotos is native from Africa through the Indian subcontinent to northern Australia. Molecular studies have shown that the Southern African N. petersiana, previously classified within subg. Brachyceras, in fact belongs to subg. Lotos where it is sister to the remainder of the species (Borsch et al. 2007). All phylogenetic analyses hitherto carried out agree on the close relationship between the pantropically distributed subg. Brachyceras and an Australian radiation of species constituting subg. Anecphya. Complex reticulate evolutionary patterns were involved in the genesis of the approximately 10-16 species of Anecphya (Löhne et al. 2008a), many of which were described only recently (Jacobs \& Porter 2007; Jacobs \& Hellquist 2006; Jacobs \& Hellquist 2011, this issue). Morphology and molecules agree on the finding that the monotypic genus Ondinea diverged rather recently from ancestors within Anecphya (Borsch et al. 2007, Löhne et al. 2009), pointing at rapid changes in floral architecture as well as organ number, probably as a consequence of changes in life form (submerged aquatic in temporal streams). Therefore, Löhne et al. (2009) transferred Ondinea purpurea, including its two subspecies, to Nymphaea.

Analyses of divergence times and historical biogeography of Nymphaeales (Yoo et al. 2005, Löhne et al. 2008b) revealed two major diversification phases during the evolution of the Nymphaeales crown group. First, there was a rapid differentiation into the three major lineages, Cabombaceae, Nuphar and the remaining Nymphaeaceae, during the Palaeocene. Secondly, the radiation of core Nymphaeaceae (Victoria, Euryale, Nymphaea incl. Ondinea) took place from the Late Oligocene to Middle Miocene. The scenario outlined by Löhne et al. (2008b) starts with a differentiation of the Nymphaea subgenera in the Northern Hemisphere and subsequent migration of subg. Hydrocallis to the New World and subg. Lotos to the Old World. During the Miocene, the subgenus Hydrocallis radiated in South America, whereas ancestors of subgenus Anecphya migrated to Australia followed by a rapid radiation. Löhne et al. (2008b) explain the present pattern of tropical disjunctions of closely related lineages as being a result of range expansion in the Northern hemisphere during the Early Tertiary and, from the Oligocene to Miocene, subsequent vicariance due to the formation of migration barriers (oceans and climatic zones). Similar scenarios have been inferred for several other pantropical angiosperm groups, such as Magnoliaceae (Azuma et al. 2001, Doyle et al. 2004), Lauraceae (Chanderbali et al. 2001) and Malphigiaceae (Davis et al. 2002, 2004).

The subgenus Brachyceras is the least understood group of water-lilies. Many taxa, especially from the Palaeotropics, have an unclear status and have not been collected for decades. A comprehensive modern treatment of the group is sorely needed to integrate the fragmentary regional information that currently exists. The $\operatorname{trn} \mathrm{T}-\operatorname{trn} \mathrm{F}$ data set of Borsch et al. (2007) included eight Brachyceras species, which at that time comprised the largest number of taxa in any phylogenetic study involving the subgenus. There were two African and one New World subclades, although their relationships remained unclear. Evidence from multiple plastid regions, mitochondrial matR, nuclear ITS and morphology placed the Neotropical N. gracilis and the African N. micrantha as sisters (Löhne et al. 2007, Borsch et al. 2008). However, the monophyly of subg. Brachyceras itself could not be resolved with any confidence in the more densely sampled trnT-trnF tree of Borsch et al. (2007). Therefore, it remains to be clarified if the pan-tropical 
water-lily species of Brachyceras are paraphyletic to subg. Anecphya or are in fact monophyletic. In order to test this, dense taxon sampling will be crucial as a random choice of few Nymphaea species is likely to lead to biased phylogenetic conclusions on the phylogenetic position of Nymphaea and on phylogenetic relationships within the genus (Löhne et al. 2007).

A complete species phylogeny of water-lilies will not only be essential for better understanding of their evolutionary diversification but also is a prerequisite to study species limits and to arrive at a complete modern species assessment. The strategy is to include all morphological entities (species and phenotypic variants) into plastid and nuclear sequence data sets. This allows a determination of all lineages and, through genomic incongruence, also of areas of the tree where hybridisation led to reticulate origin of species. Hybrid speciation in conjunction with allopolyploidisation is evident within Nymphaea subgenera Anecphya (Löhne et al. 2009) and Nymphaea (Volkova et al. 2010). Representation of individuals from throughout the range of species is necessary to detect geographical differentiation within monophyletic species, as evident in the widespread North American Nymphaea odorata (Woods et al. 2005), and incomplete lineage sorting. This may be a factor in the Australian subg. Anecphya (Löhne et al. 2008a). Reticulation or unequal lineage sorting, however, has not yet been detected within other water-lily lineages but this could simply be caused by limitations in sampling.

Here we use the plastid $\operatorname{trn} \mathrm{T}-\operatorname{trn} \mathrm{F}$ and nuclear ITS regions to construct a comprehensive sequence data set with the aim of including as many taxa as possible rather than limiting the size of the taxon set in order to increase the number of characters. Insufficiently resolved clades or subclades within the respective trees can then be studied later with additional approaches including genomic fingerprinting techniques and algorithms not a priori relying on dichotomous evolutionary patterns. Aims of this study are therefore to include more samples of subg. Brachyceras and to test (1) how the various lineages of Brachyceras are related to each other and to the Australian Anecphya clade, and (2) the extent to which hitherto unsampled taxa of Brachyceras can be distinguished by DNA sequence data.

\section{Material and Methods}

\section{Taxon sampling}

The $\operatorname{trn} \mathrm{T}-\operatorname{trn} \mathrm{F}$ dataset used in this study comprises 86 species of Nymphaeales, representing both genera of the Cabombaceae (Brasenia, Cabomba) as outgroup taxa, each genus of the Nymphaeaceae (Barclaya, Euryale, Nuphar, Nymphaea, Victoria), and within the genus Nymphaea, each of the five subgenera (Anecphya, Brachyceras, Hydrocallis, Lotos, Nymphaea). Nymphaea ondinea, previously separated from Nymphaea as a distinct genus, is also included in our data sets.

A subset of 43 of these taxa was employed for analysing the relationships of subg. Brachyceras and Anecphya using the nuclear ITS marker. Here, two species of subg. Hydrocallis (N. amazonum, N. jamesoniana) were used as outgroup taxa, with all available taxa of Anecphya and Brachyceras forming the ingroup. New samples were sequenced for both $\operatorname{trn} \mathrm{T}-\operatorname{trn} \mathrm{F}$ and ITS in this study. Additionally, published sequences from the authors' previous studies were used to complement the data sets. All taxa used 
in this study, including information on origin of the material, voucher specimens and EMBL/Genbank accession numbers, are listed in Appendix 1.

\section{DNA isolation, amplification and sequencing}

DNA was isolated from silica-gel-dried leaf tissue using the triple extraction method of Borsch et al. (2003). The chloroplast genomic region $\operatorname{trn} \mathrm{T}-\operatorname{trn} \mathrm{F}$ is widely used for phylogenetic analyses and spans the intergenic spacer between $\operatorname{trn} \mathrm{T}$ and $\operatorname{trn} \mathrm{L}$, the $\operatorname{trn} \mathrm{L}$ gene including its intron as well as the spacer between $\operatorname{tr} n \mathrm{~L}$ and $\operatorname{trn} \mathrm{F}$. We amplified this region in two fragments using the primers rps4-5R (Sauquet et al. 2003) and trnL110R (Borsch et al. 2003) for the 5'-fragment and the primers C and F (Taberlet et al. 1991) for the 3'-fragment. In addition to the amplification primers, the internal sequencing primers D and E (Taberlet et al. 1991) were used to read through long poly-TA stretches in the p8 stem loop of the trnL intron (see Borsch et al. 2007 for a detailed analysis of this region).The nuclear marker region ITS spans the internal transcribed spacer 1 (ITS1) between $18 \mathrm{~S}$ and 5.8S rDNA, the 5.8S rDNA itself, and the internal transcribed spacer 2 (ITS2) between $5.8 \mathrm{~S}$ and $26 \mathrm{~S}$ rDNA. Amplification and sequencing of this region was done using the standard primers ITS4 and ITS5 (White et al. 1990) and following the procedure outlined in Löhne et al. (2008a).

\section{Alignment and indel coding}

Sequences were aligned manually with PhyDe $^{\circledR}$ version 0.9.95 (Müller et al. 2007) following the rules outlined in Löhne and Borsch (2005). For ITS, sequences of Amborella, Austrobaileya, Illicium, Schisandra and Kadsura could not be aligned with the sequences of Nymphaeales (at least for the major parts of the region). Therefore, only ITS sequences of representatives of the subgenera Brachyceras and Anecphya, with two representatives of subg. Hydrocallis as outgroup, were aligned and analysed. Mutational hotspots (after Borsch et al. 2003) were excluded from analysis. All length mutations in ITS were coded automatically in a "01"-matrix with SeqState version 1.4 (Müller 2005), applying the "simple indel coding" strategy after Simmons and Ochoterena (2000). The indel matrix was appended to the sequence matrix for Maximum Parsimony and Bayesian analyses. Thus, the final ITS matrix contained 767 characters (707 nucleotide characters and 60 indels).

Alignment and indel coding of the $\operatorname{trn} \mathrm{T}-\operatorname{trn} \mathrm{F}$ regions was done in the same way. Additionally, the $\mathrm{p} 8$ stem-loop region within the $\operatorname{tr} \mathrm{L}$ intron (originally excluded as a hotspot from the main matrix, see also Borsch et al. 2007) was aligned separately for each subgenus and appended to the matrix. This allowed the inclusion of nucleotide positions and length mutations, which are potentially informative within the subgenera. The final $t r n \mathrm{~T}-t r n \mathrm{~F}$ matrix comprised 2077 characters (1953 nucleotide positions from trnT-trnF, including the p8 region, and 124 indels).

\section{Phylogenetic and dating analyses}

The two data sets of Nymphaea s.l. were analysed separately. Maximum parsimony (MP) ratchet analyses were conducted with command files generated by PRAP (Müller 2004) and then executed with PAUP* version 4.0b10 (Swofford 2002). The ratchet settings were 200 iterations, weight 2 , weighted $=25 \%$, and 10 random addition cycles. Heuristic search parameters were simple stepwise addition, saving only one of the shortest trees per random-addition cycle and increasing the maximum number of trees 
automatically by 100 . Node support was estimated through jackknifing (JK) 10,000 replicates (simple addition, keeping 1 tree per replicate, deleting $36.8 \%$ of characters in each replicate).

For Bayesian analysis, models of molecular evolution in ITS and the trnT-trnF region, respectively, were determined using MrModeltest version 2.2 (Nylander 2004) according to the Akaike information criterion. The following models were selected: GTR+G for ITS and the $\operatorname{trn} \mathrm{L}$ intron, GTR+I for the $\operatorname{trn} \mathrm{L}-\operatorname{trn} \mathrm{F}$ spacer, GTR for the $\operatorname{trn} \mathrm{T}-\operatorname{trn\mathrm {L}}$ spacer, JC for the $\operatorname{trn} \mathrm{L}$ gene, and F81 for the $\mathrm{p} 8$ region within the $\operatorname{trn} \mathrm{L}$ intron. Bayesian analyses of the total evidence data sets (substitutions plus indels) were performed using MrBayes version 3.1.2 (Ronquist \& Huelsenbeck 2003), with the binary model applied to the indel partition. Analyses settings were as follows: four runs with four chains and $1,000,000$ generations each, saving one tree per 100 generations. During the calculation, tree probabilities converged to a stable value after 38,000 generations for ITS and after 15,000 generations for $\operatorname{trn} \mathrm{T}-\operatorname{trn} \mathrm{F}$; thus, the burn in was set to 380 and 150, respectively.

Divergence times were inferred using the integrated relaxed clock approach implemented in the program BEAST version 1.5.4 (Drummond \& Rambaut 2007). Instead of rate priors, two calibration points were used for each data set. For $\operatorname{trn} \mathrm{T}-\operatorname{trn} \mathrm{F}$ the minimum age for the Nuphar crown group was set as $52 \pm 1$ Mya (Chen et al. 2004; Nuphar wutuensis is the oldest known fossil record of Nuphar). The Nymphaea crown group was set to have a minimum age of $33 \pm 1$ Mya. This is based on Nymphaea liminis as the oldest fossil seeds that can be unambiguously assigned to Nymphaea (dated as Upper Eocene/Lower Oligocene; Collinson 1980). The time of the Eocene/Oligocene boundary is drawn from Berggren et al. (1995). This set of taxa assigned to Nymphaea was not specified as monophyletic for the calculations. For the ITS data set, minimum ages for the crown group of the Brachyceras-Anecphya-clade were set as $24.7 \pm 5.8$ Mya and for the Anecphya clade as $19.6 \pm 6.5$ Mya based on the dated trnT-trnF tree of this study (Fig. 2). Models of molecular evolution were chosen for each partition as depicted by MrModeltest (see above). However, since the programme BEAST does not include a model for binary matrices we excluded the indel characters from both data sets. Thus, the matrices containing only nucleotide characters were analysed with BEAST. Rates for each branch were drawn independently from a lognormal distribution (Drummond et al. 2006). A Yule speciation model was assumed and a random starting tree was used. Analyses were performed for 10,000,000 generations, saving one tree every 1000 generations. The burn in was set to $10 \%$ yielding 9000 trees. The maximum clade credibility tree was calculated with TreeAnnotator v. 1.4.8 (Drummond \& Rambaut 2007), setting the posterior probability limit to 0.7. Trees were rooted with Cabombaceae in the trnT-trnF analysis and with Nymphaea amazonum and $N$. jamesoniana in the ITS analysis.

\section{Results}

\section{Trees obtained from trnT-trnF}

Maximum Parsimony (MP) analysis of the chloroplast marker trnT-trnF yielded 114 shortest trees with a tree length of 543 steps. Figure 1 shows the strict consensus of these 114 trees with Jackknife support values above branches. The consensus tree of the Bayesian Analysis using MrBayes (BA) is not shown since it is largely congruent 


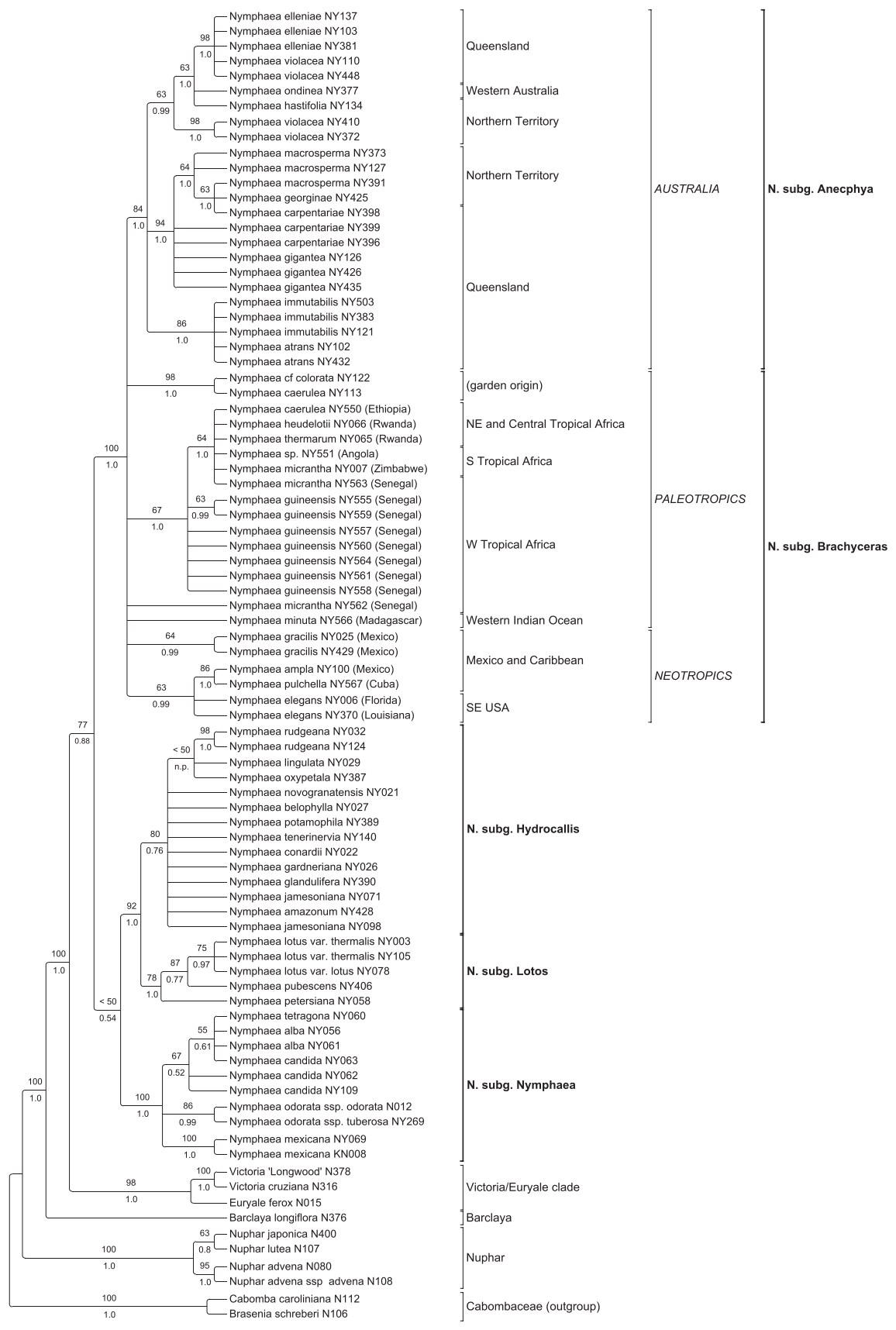

Fig. 1. Phylogenetic relationships within Nymphaea and Nymphaeaceae as inferred from the plastid marker trn $\mathrm{T}-\operatorname{trn} \mathrm{F}$. The tree shown is the strict consensus of 114 shortest trees obtained with Maximum Parsimony analysis. Jackknife values are given above branches. Posterior probabilities as obtained from Bayesian analysis with MrBayes (tree not shown) are given below branches. Nodes, which are not present in the Bayesian tree, are marked with n.p. (not present). 


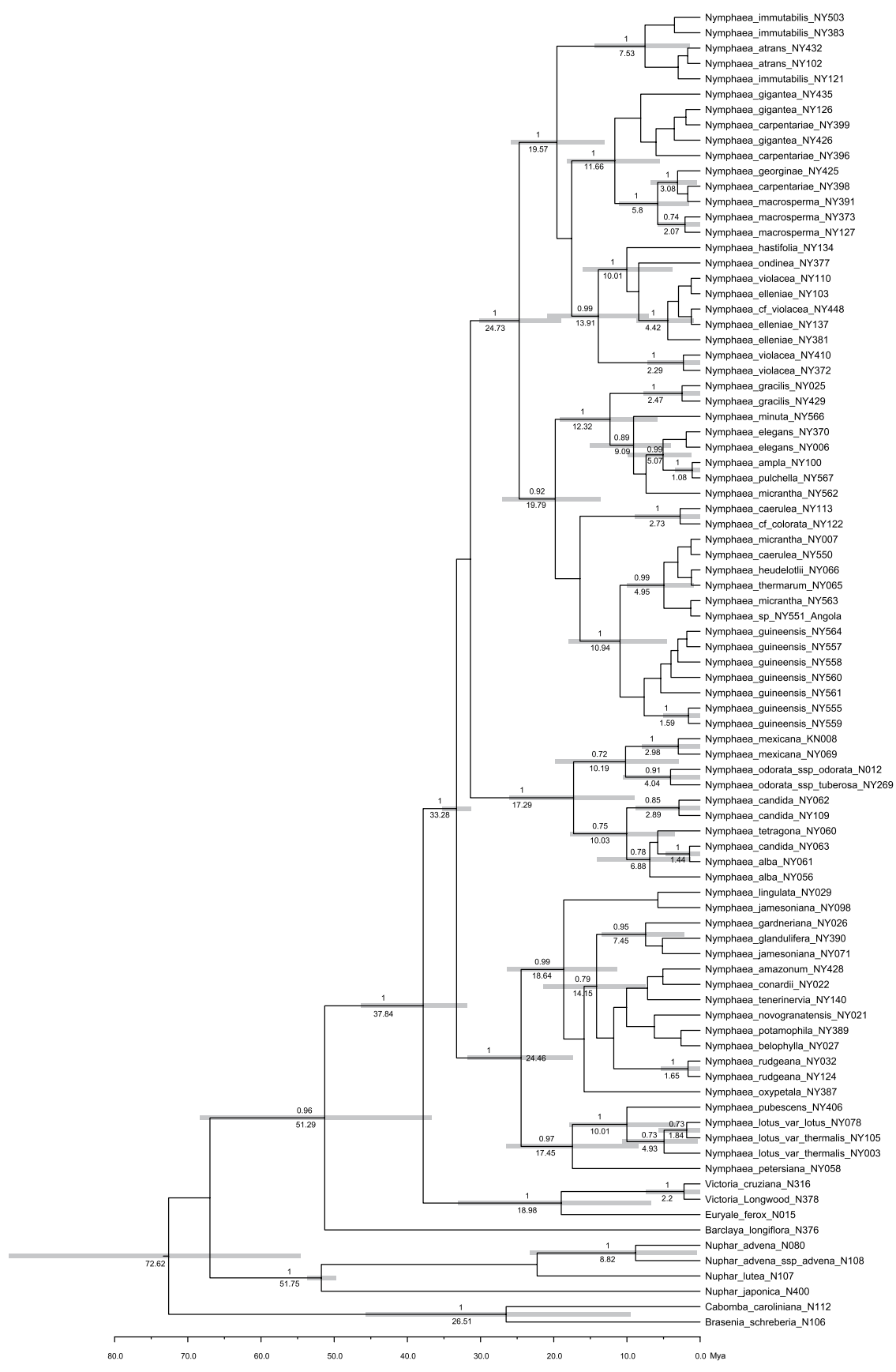

Fig. 2. Summary tree from BEAST analysis of the plastid marker trnT-trnF. Log-normal prior of 52.0 \pm 1 million years was set for the most recent common ancestor (MRCA) of Nuphar and $33.0 \pm 1$ million years for the MRCA of Nymphaea, according to the fossil record (see text). Posterior probability values above 0.7 are presented above each node. The inferred age of each node is given below the respective branch, while the bars represent $95 \%$ confidence intervals of the inferred ages. 
with the MP tree. Posterior Probabilities, as obtained with MrBayes, are instead given below the branches of the MP tree. There is only one node present in the MP that is not present in the BA tree (marked with n.p. in Fig. 1) and a few poorly supported terminal nodes present in the BA but not in the MP tree (not shown).

The maximum credibility tree obtained from the BEAST analysis (Fig. 2) differs from the MP and BA trees (Fig. 1) by depicting Brachyceras as monophyletic, although the relevant node receives only $0.92 \mathrm{PP}$. The BEAST analysis indicates an age of $24.7 \pm 5.7$ Mya for the Anecphya-Brachyceras clade, 19.6 \pm 6.5 Mya for the Anecphya crown group and a similar age (19.8 $\pm 6.7 \mathrm{Mya})$ for the Brachyceras crown group.

\section{Trees obtained from ITS}

The ITS data set comprises more potentially parsimony informative characters than $\operatorname{trn} \mathrm{T}-\operatorname{trn} \mathrm{F}$ (250 within ITS, 190 within the $\operatorname{trn} \mathrm{T}-\operatorname{trn} \mathrm{F}$ data set), although it has less than half the number of base pairs. Due to the variability of this nuclear marker, it is not possible to align complete ITS sequences of the Anecphya-Brachyceras clade with sequences from other subgenera of Nymphaea, let alone with other Nymphaeaceae or Cabombaceae. However, ITS is useful for investigating phylogenetic relationships within the Anecphya-Brachyceras clade. Figure 3 shows the strict consensus of 4 shortest trees (466 steps). As with $\operatorname{trn} \mathrm{T}-\mathrm{trn \textrm {F }}$, Bayesian analysis with MrBayes yielded a largely congruent tree (not shown), with only very few, poorly supported terminal nodes not present in both trees. However, the topologies of the ITS tree and the respective part of the plastid tree (Anecphya-Brachyceras clade) are not fully congruent. There are, for example, some differences in the position of the $N$. violacea samples within subg. Anecphya. These are not discussed here, since the complex evolutionary patterns in this subgenus have been discussed earlier by Löhne et al. (2008).

The ITS data set was also analysed with BEAST, using the ages estimated with the trnT$\operatorname{trn} \mathrm{F}$ data set for the Anecphya-Brachyceras clade and the Anecphya crown group as calibration points. The BEAST summary tree (Fig. 4) shows the same topology as the MP/BA tree (Fig. 3).

\section{Discussion}

\section{Relationships within the Anecphya-Brachyceras clade}

The dense taxon sampling of water-lilies provides some indication that both subg. Anecphya and subg. Brachyceras are monophyletic. Previously, neither maximum parsimony nor Bayesian tree inference applied to a smaller $\operatorname{trn} \mathrm{T}-\operatorname{trn} \mathrm{F}$ data set had recovered a subg. Brachyceras clade (Borsch et al. 2007) whereas a subg. Anecphya clade consistently received maximum support. This pattern is also evident for trees inferred from the extended trn $\mathrm{T}-\operatorname{trn} \mathrm{F}$ data set in this study, although the maximum credibility tree calculated with BEAST (Fig. 2) depicts Brachyceras as monophyletic. It has to be noted that this tree gives an alternative hypothesis which is based on a different approach to summarising trees based on the criterion of highest product of posterior probabilities as implemented in the BEAST package. In any case the monophyly of subg. Brachyceras needs further testing using additional plastid data. 
Internal relationships of the subg. Brachyceras clade in the maximum credibility tree, however, are unique in suggesting a "mixed" New World lineage (1.00 PP) also containing the Madagascan N. minuta and one deviant sample of N. micrantha (NY562). All samples of N. guineensis appear in a lineage sister to most other African species, together gaining 1.00 Posterior Probability from the BEAST analysis.

In general, Bayesian Posterior Probabilities are prone to over credit nodes as is evident from simulation (Suzuki et al. 2002) and empirical analyses (Simmons et al. 2004). Recent simulation studies indicate that Bayesian Inference may also group long branches together, especially when sequence sites evolve heterogeneously (Kolaczkowski \& Thornton 2009). In the shallow Brachyceras clade, sequences exhibit not only very low overall distances but also many autapomorphic mutations that hamper correct model assessment. The BEAST topology (Fig. 2) and similarly the Bayesian tree obtained with MrBayes (not shown) must therefore be interpreted with caution, and the high posterior probabilities may not necessarily indicate correctly resolved nodes.

In contrast, nuclear ITS sequences yield a well-resolved and supported MP tree (Fig. 3), where both subgenera (Anecphya and Brachyceras) are revealed as well supported monophyletic clades. All species of subg. Brachyceras share characteristic morphological features that support their separation from subg. Anecphya: there are free carpellary appendages and much broader filaments in subg. Brachyceras, which are absent or filamentous in subg. Anecphya. The ITS tree shows that within Brachyceras there is a clade, comprising all samples of N. guineensis and N. minuta, which is sister to the remaining samples. The neotropical species N. ampla, N. elegans, N. gracilis and N. pulchella occur in a well supported clade completely nested within African taxa. In subgenus Anecphya, two major clades corresponding to the "small seeded group" (comprising N. macrosperma, N. carpentariae, N. georginae, N. gigantea, N. immutabilis and $N$. atrans) and a "large seeded group" (N. violacea, N. elleniae, N. hastifolia and $N$. ondinea) are recovered as in the earlier more comprehensive analysis by Löhne et al. (2008a). The "small seeded group" has been separated from Anecphya as a distinct subgenus Confluentes by Jacobs (2007). While reticulate evolutionary patterns are evident in subg. Anecphya (Löhne et al. 2008a), there are also some hints on reticulation within subg. Brachyceras. This applies especially to the position of N. minuta, which is depicted sister to $N$. guineensis by the nuclear marker but nested within the neotropical lineage in the trnT-trnF BEAST tree (Fig. 2). However, this finding can be only preliminary because phylogenetic structure in the trnT-trnF sequences is still insufficient (as evident from the polytomy in the MP tree, Fig. 1).

\section{Biogeography of subgenus Brachyceras: the neotropical lineage "out-of-Africa"}

The addition of further subg. Brachyceras species, especially to the nuclear ITS tree of Borsch et al. (2008), provides evidence that the Neotropical species of Brachyceras form a lineage nested within the African taxa (Figs 3 \& 4). Previous phylogenetic studies of Nymphaea with a smaller taxon sampling showed N. heudelotii (Africa) sister to N. gracilis plus N. ampla (Löhne et al. 2007, Borsch et al. 2008). The plastid trnT$\operatorname{trn} \mathrm{F}$ trees of this study (Figs $1 \& 2$ ), however, do not allow any insights on historical plant migration patterns within Brachyceras due to limited resolution and support. However, the ITS tree suggests an origin "out-of-Africa" of the neotropical Brachyceras sublineage (Fig. 3). 
Molecular dating based on a matK tree of 25 Nymphaeales taxa (Löhne et al. 2008b) suggested an age for the Anecphya-Brachyceras crown group of $9.9 \pm 6.5$ Mya. Even if the closest palaeotropical relatives of the New World Brachyceras lineage are not yet precisely known, it is obvious that their split must be younger. Our estimate with the fossil calibrated minimum ages of Nuphar (52 Mya; Nuphar wutuensis) and Nymphaea (33 Mya, Nymphaea liminis) using a much more densely sampled trnT-trnF data set and BEAST (Fig. 2) increases the hypothesised age of the Anecphya-Brachyceras crown group to $24.7 \pm 5.8$ Mya. Differences may be caused by the denser taxon sampling in this study as better taxon sampling tends to yield older nodal estimates (Linder et al. 2005). Accordingly, our trn T-trnF analysis hypothesises a split of a Brachyceras sublineage mainly composed of New World species to have already taken place $19.6 \pm$ 6.5 Mya. However, this topology should be viewed with caution (see above). A dating approach using the ITS data set of Anecphya-Brachyceras has some limits because there are no fossils known for this lineage, and previously calculated node ages including their Credibility Intervals need to be used as calibration points. The revealed minimum
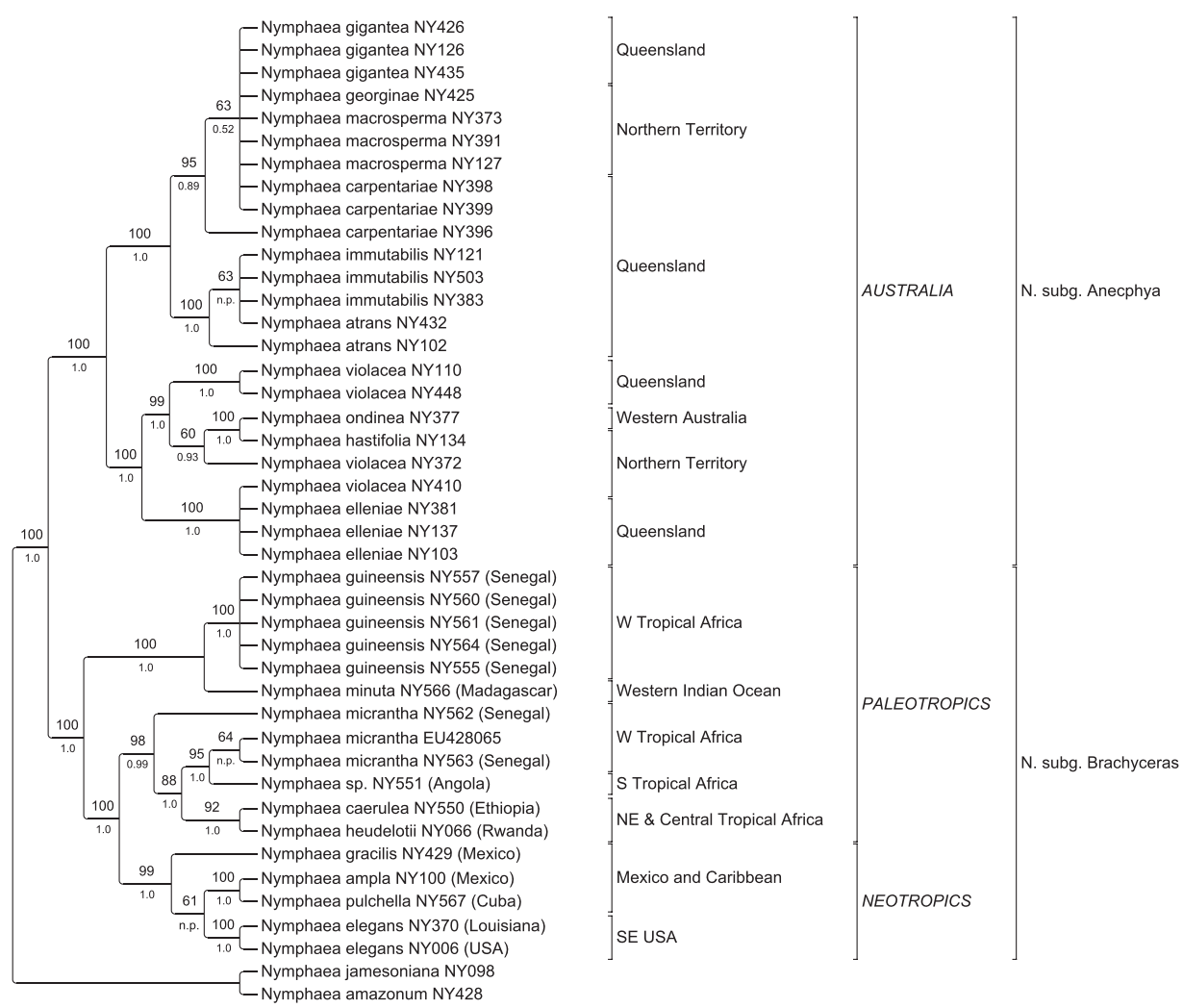

Fig. 3. Phylogeny of Nymphaea subg. Brachyceras and subg. Anecphya as inferred from the nuclear marker ITS. Tree tree shown is the strict consensus of four shortest trees obtained by Maximum Parsimony analysis. Jackknife values are given above branches. Posterior probabilities as obtained from Bayesian analysis with MrBayes (tree not shown) are given below branches. Nodes, which are not present in the Bayesian tree, are marked with n.p. (not present). 
ages within N. subg. Brachyceras and Anecphya are about twice as old as calculated using a matK tree that, in comparison, sampled only $30 \%$ of the taxa (Löhne et al. 2008b). Nevertheless, the split of a clear New World Brachyceras lineage is found to have occurred $10 \pm 6$ Mya (Fig. 4), and thus roughly falls into the same time range as expected from plastid data by Löhne et al. (2008b).

Plant migrations from Africa to the Neotropics are known from various angiosperm families and appear to be even more important in explaining African-Neotropical biogeographic relations than vicariance (Erkens et al. 2009). This is indicated by inferred origins of lineages considerably younger than 100-110 Mya, when the opening of the Atlantic Ocean was initiated (McLoughlin 2001). In several families, early to middle Eocene diversification is reconstructed and migration of angiosperms

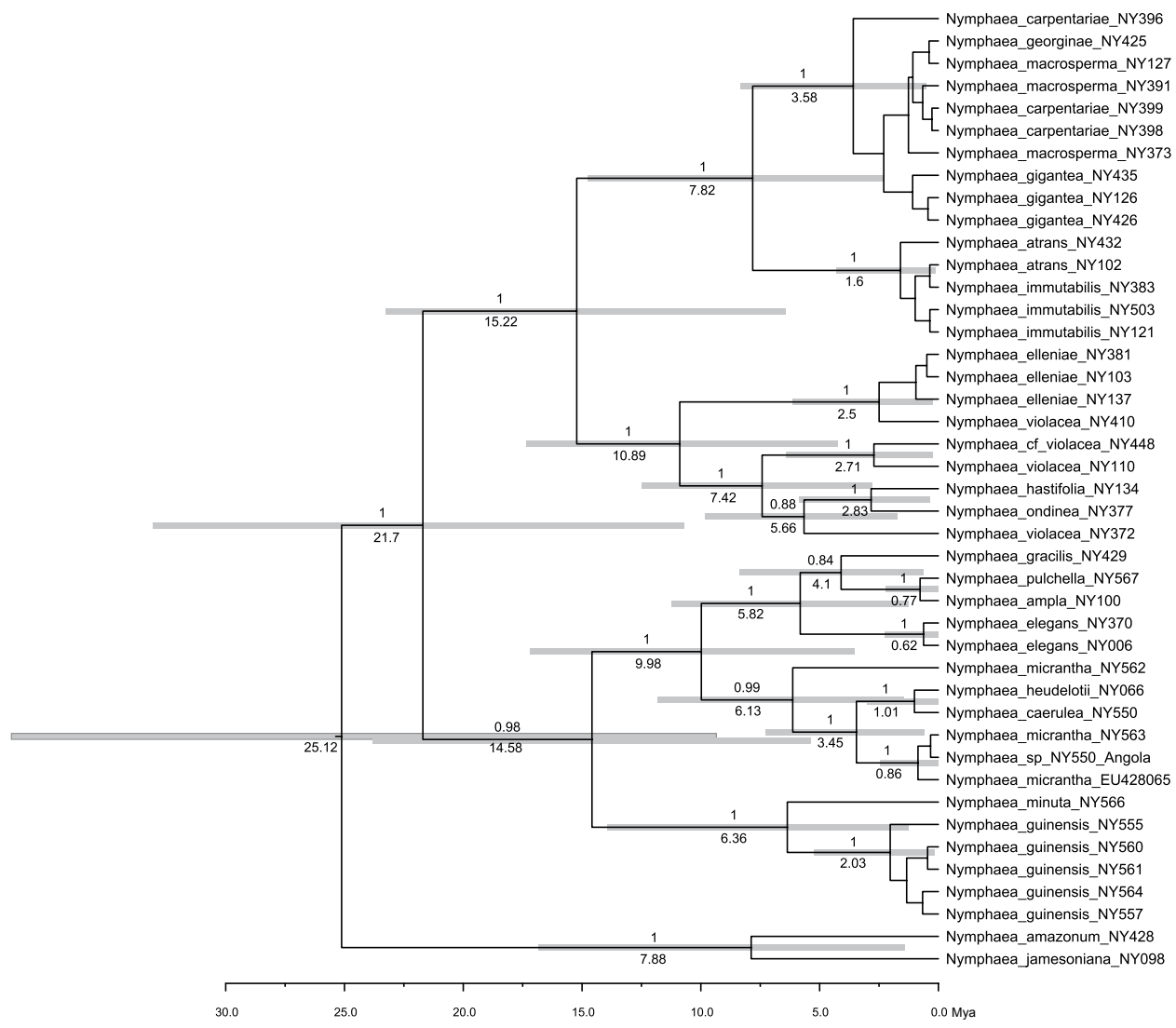

Fig. 4. Summary tree from BEAST analysis of the nuclear marker ITS. Log-normal prior of 24.7 \pm 5.8 Mya was set for the MRCA of the ingroup (the Brachyceras-Anecphya clade) and $19.6 \pm$ 6.5 Mya for the MRCA of subg. Anecphya. These dates were taken from the previous analysis of the $\operatorname{trn} \mathrm{T}-\operatorname{trn} \mathrm{F}$ dataset, in order to allow at least a rough estimation of ages within this group. Posterior probability values above 0.7 are presented above each node. The inferred age of each node is given below the respective branch, while the bars represent $95 \%$ confidence intervals of the inferred ages. 
adapted to tropical climates proceeded via the North Atlantic or the Bering Land Bridges. This possibility finally ceased during the Oligocene with the cooling of the northern hemisphere (Morley 2003). Meliaceae were shown to have dispersed in the Eocene via Beringia from Africa into the New World (Müllner et al. 2006). For Malpighiaceae, a "Laurasian migration route" via a boreotropical connection between North America and Eurasia during the Eocene was hypothesised (Davis et al. 2002). For Melastomataceae, Renner et al. (2001) reported the arrival of boreotropical taxa in southern continental New World areas in the Oligocene and Miocene. Such a scenario may be true for the ancestor of the Neotropical night blooming water-lilies (Löhne et al. $2008 \mathrm{~b}$ ) that subsequently produced the radiation of the 14 species of subg. Hydrocallis distributed from the Caribbean and Central America to South America.

How did the ancestor of the Neotropical Brachyceras species reach the Western hemisphere? Theoretically, there are three possible migrational routes (Morley 2003, Erkens et al. 2009). The first assumes spread over a North Atlantic Land Bridge (Tiffney \& Manchester 2001) around a climatic optimum in the Eocene (45-55 Mya). This certainly predates the origin of the Brachyceras lineage. Alternatively, plants could have spread over the Bering Land Bridge. This connection existed well into the Pliocene (Tiffney \& Manchester 2001), and, time wise, could have been a possible route. Löhne et al. (2008b) argued that several Nymphaeales taxa show adaptations to seasonal habitats. Tropical or paratropical ancestral Brachyceras species could have survived dark winters at northern latitudes in a dormant state. The present day distribution of Brachyceras, with most Neotropical taxa in Mexico, the Caribbean and Central America, some even reaching warm-temperate North America, may be indicative of a radiation in this area with subsequent spread of only a few taxa into South America. A phylogeographic examination of the Nymphaea ampla - N. pulchella species complex would be interesting in this context. Nymphaea pulchella was recently resurrected as a distinct species based on leaf and seed morphology (Wiersema et al. 2008) and is one of only two taxa ranging well into South America. Since the neotropical Brachyceras sublineage appears as a terminal clade within an African stock of Brachyceras (Fig. 3), the acceptance of a Beringian migrational route would also imply that Asian taxa of subg. Brachyceras (e.g. N. nouchali) have an African origin. The third possibility could have been dispersal from Africa to the New World tropics across the ocean, either facilitated by islands as stepping stones until the Miocene (Tiffney \& Manchester 2001, Morley 2003) or by immediate long distance dispersal by unknown vectors. Seed dispersal across the Atlantic ocean by wind and sea currents was hypothesised by Renner (2004) for a number of angiosperm genera (e.g., Elaeis / Arecaceae, Commiphora / Burseraceae). Nymphaea seeds can float and this is even supported by specialised arils (Wiersema 1987, Borsch et al. 2008) but nothing is known about the influence of salt water on their seed viability. However, since our divergence time estimates in Nymphaea are rather too young than too old, a step by step long distance dispersal of Brachyceras species into the New World via the Beringian Land Bridge in a still suitable climate may well be a possible explanation.

Another interesting pattern is the close relationship of N. guineensis from West Africa and the Madagascan endemic N. minuta inferred by ITS (Fig. 3). This would imply a trans-African disjunction of closely related lineages, as observed in several other plant groups (see Sanmartín et al. 2010 for overview). However, in the trnT-trnF BEAST tree (Fig. 2), Nymphaea minuta is nested within a clade with the Neotropical species; but this position is not recovered by the MP analysis (Fig. 1). Thus, further investigation 
of phylogenetic relationships, preferably at population levels, will be necessary to draw sound conclusions on the biographic history of Nymphaea subg. Brachyceras in Africa.

Further sequence data from all genomic compartments will be needed to test the monophyly of subg. Brachyceras, and its internal relationships. Tree inference using combined data sets of genomic regions selected for high phylogenetic structure will yield improved node confidence (Borsch \& Quandt 2008). A larger number of concatenated genomic regions is also expected to produce better time estimates with smaller credibility intervals using relaxed clock methods (Battistuzzi et al. 2010). Our data also show a trend to relatively higher Credibility Intervals for younger nodes. Dating of shallow phylogenies, as for example is the case within Brachyceras, will certainly benefit from a more representative sampling of sequence characters that will allow calculation of more accurate posterior intervals (Brown \& Yang 2010). Increasing the molecular data sets of Nymphaea will therefore be an important future task.

\section{Molecular systematics of water-lilies: Towards a complete species tree}

This study presents the most comprehensive data set for Nymphaea to date, comprising approximately $75 \%$ of all currently known species. It will be a major task for future collaborative research to include all taxa for a complete species tree. A complete species tree will on the one hand provide the necessary backbone for species identification based on DNA markers (bar codes). It will also provide the molecular basis for evaluating species concepts in Nymphaea and for compiling a comprehensive monograph of the genus Nymphaea based on information from morphological, molecular and ecological data.

The two described genomic markers trnT-trnF and ITS show great potential for molecular species identification (DNA bar-coding). Within $\operatorname{trn} \mathrm{T}-t r n \mathrm{~F}$, there are the AT-rich sections of the $\operatorname{rn} \mathrm{L}$ intron (especially the $\mathrm{p} 8$ stem-loop region) that provide sufficient information for species identification. However, as a prerequisite an evaluation of species limits and population level studies across the species' ranges is needed. This is especially important because reticulate evolution has been identified in subg. Anecphya (Löhne et al. 2008a) and recently also shown for the temperate subg. Nymphaea (Volkova et al. 2010). Further research is also needed to see if allopolyploids are involved in the evolution of Nymphaea and its subgenera. Including more information from plastid DNA markers seems to be most promising in order to unravel the complex evolutionary patterns within Nymphaea. However, it will also be crucial to analyse how morphological and other biological characters (e.g., pollination biology, vegetative adaptations, distribution) correlate with the complete species tree based on molecular markers. Therefore, it will be helpful to have all sequence data collected in a curated data base linked to geo-referenced specimen information and, if possible, population data accompanying the specimens.

After more than a century since the seminal work of Conard (1905), exploration and description of new water-lily species has still not finished. As evident from Fig. 5, one quarter of the currently accepted species were described in the last 30 years. Main contributions in this sense were the monograph of Nymphaea subg. Hydrocallis by Wiersema (1987, see also Wiersema et al. 2008) and the contributions by Surrey W. L. Jacobs on Nymphaea subg. Anecphya (Jacobs 1992, 1994, 2007, Jacobs \& Hellquist 2006, Jacobs \& Porter 2007). There are still several taxa of uncertain status, especially within the least understood subg. Brachyceras but also in subg. Lotos, where the identity 

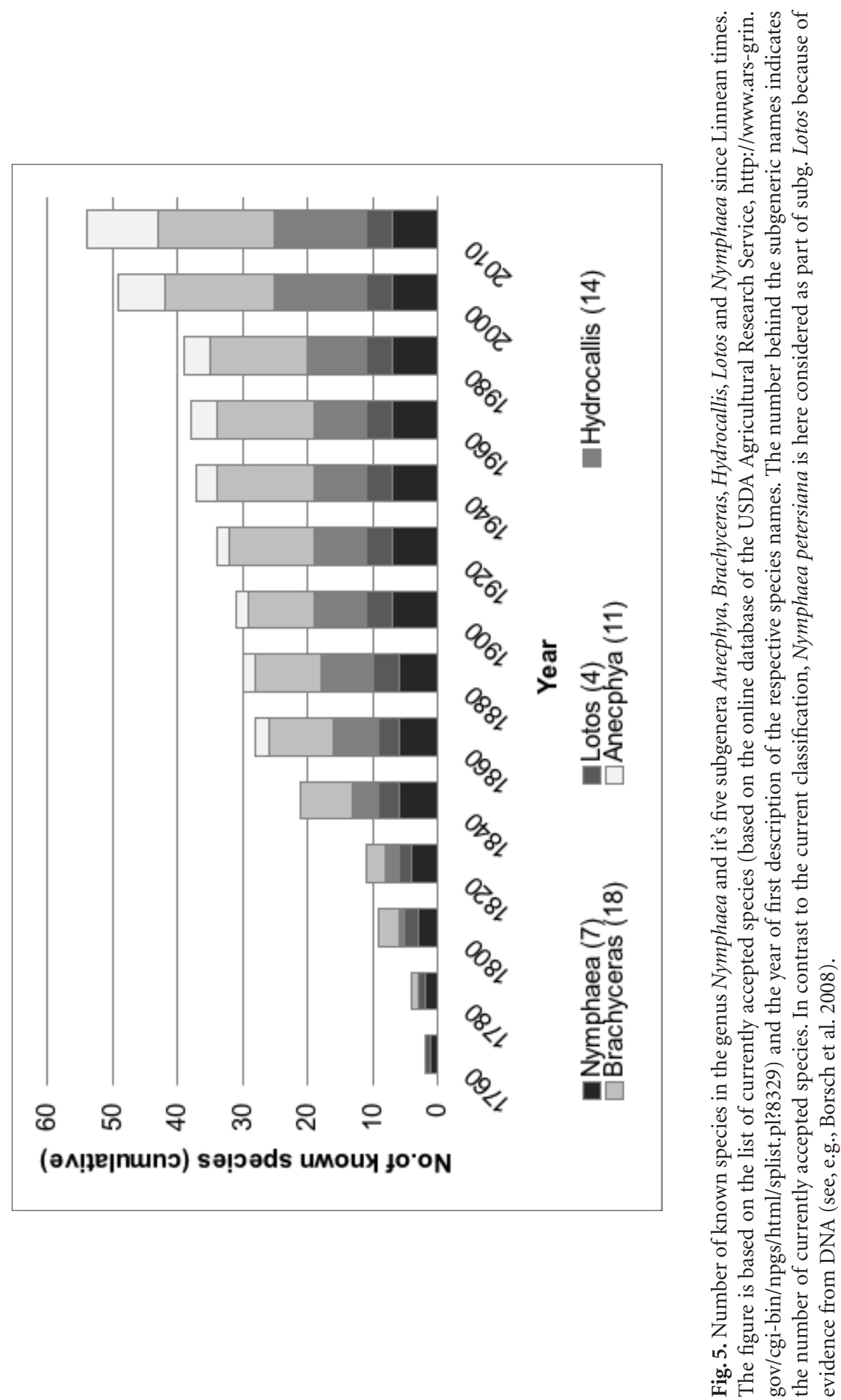
of N. rubra needs to be verified (Mitra \& Subramanyam 1982, Venu et al. 2003). Thus, it might be expected that future work on these two subgenera will again alter (and probably increase) the total number of species in the genus Nymphaea. Additionally, our present study adds further interesting questions, especially with respect to the biogeographical history of subg. Brachyceras.

In conclusion, it must be stated that a comprehensive monograph of Nymphaea with data on species distribution, ecology and conservation status is very much needed. Such an undertaking should be and actually can only result from the joint effort and expertise from an international working group on Nymphaea and the Nymphaeales.

\section{Acknowledgments}

We appreciate the help of Bettina Giesicke (Berlin) who generated the new sequences in the lab; and the Botanic Garden Berlin-Dahlem, especially Ms. Daniela Bunde, for taking care of the Nymphaea living collection. Furthermore, we thank Carlos Magdalena, Royal Botanic Gardens Kew, for providing seeds of Nymphaea minuta.

\section{References}

Azuma H, García-Franco JG, Rico-Gray V \& Thien LB (2001) Molecular phylogeny of the Magnoliaceae: The biogeography of tropical and temperate disjunctions. American Journal of Botany 88: 2275-2285.

Battistuzzi FU, Filipski A, Hedges SB \& Kumar S (2010) Performance of relaxed-clock methods in estimating evolutionary divergence times and their credibility intervals. Molecular Biology and Evolution 27: 1289-1300.

Berggren WA, Kent DV, Swisher CC \& Aubry PP (1995) A revised Cenozoic geochronology and chronostratigraphy. Pp. 129-212 in Berggren WA, Kent DV, Swisher CC, Aubry PP \& Hardenbol J (eds) Geochronology, time scales and global stratigraphic correlation. (SEPM Spec. Publ.: Tulsa)

Borsch T, Hilu KW, Quandt D, Wilde V, Neinhuis C \& Barthlott W (2003) Non-coding plastid $\operatorname{trn} T-\operatorname{trn} F$ sequences reveal a well resolved phylogeny of basal angiosperms. Journal of Evolutionary Biology 16: 558-576.

Borsch T, Hilu KW, Wiersema JH, Löhne C, Barthlott W \& Wilde V (2007) Phylogeny of Nymphaea (Nymphaeaceae): evidence from substitutions and microstructural changes of the chloroplast trnT-F region. International Journal of Plant Sciences 168: 639-671.

Borsch T, Löhne C \& Wiersema JW (2008) Phylogeny and evolutionary patterns in Nymphaeales: integrating genes, genomes and morphology. Taxon 57: 1052-1081.

Borsch T \& Quandt D (2008) Mutational dynamics and phylogenetic utility of non-coding chloroplast DNA. Plant Systematics and Evolution 282: 169-199.

Brown RP \& Yang Z (2010) Bayesian dating of shallow phylogenies with a relaxed clock. Systematic Biology 59: 119-131.

Chanderbali AS, Van der Werff H \& Renner SS (2001) Phylogeny and historical biogeography of Lauraceae: evidence from the chloroplast and nuclear genomes. Annals of the Missouri Botanical Garden 88: 104-134.

Chen I, Manchester SR \& Chen Z (2004) Anatomically preserved seeds of Nuphar (Nymphaeaceae) from the Early Eocene of Wutu, Shandong Province, China. American Journal of Botany 91: $1265-1272$.

Collinson ME (1980) Recent and Tertiary seeds of the Nymphaeaceae sensu lato with a revision of Brasenia ovula (Brong.) Reid and Chandler. Annals of Botany 46: 603-632.

Conard HS (1905) The waterlilies: a monograph of the genus Nymphaea. Publications of the Carnegie Institutions of Washington 4: 1-279. 
Davis CC, Bell CD, Mathews S \& Donoghue MJ (2002) Laurasian migration explains Gondwanan disjunctions: evidence from Malpighiaceae. Proceedings of the National Academy of Sciences of the United States of America 99: 6833-6837.

Davis CC, Fritsch PW, Bell CD \& Mathews S (2004) High-latitude tertiary migrations of an exclusively tropical clade: evidence from Malpighiaceae. International Journal of Plant Sciences 165: S107-S121.

Doyle JA, Sauquet H, Scharaschkin T \& Le Thomas A (2004) Phylogeny, molecular and fossil dating, and the biogeographic history of Annonaceae and Myristicaceae (Magnoliales). International Journal of Plant Sciences 165: S55-S67.

Drummond AJ \& Rambaut A (2007) BEAST: Bayesian evolutionary analysis by sampling trees. BMC Evolutionary Biology 7: 214

Drummond AJ, Ho SY, Phillips MJ \& Rambaut A (2006) Relaxed phylogenetics and dating with confidence. PloS Biology 4: e88

Erkens RHJ, Maas JW \& Couvreuer TLP (2009) From Africa via Europe to South America: migrational route of a species-rich genus of Neotropical lowland rain forest trees (Guatteria, Annonaceae). Journal of Biogeography 36: 2338-2352.

Jacobs SWL (1992) New species, lectotypes and synonyms of Australasian Nymphaea (Nymphaeaceae). Telopea 4: 635-641.

Jacobs SWL (1994) Further notes on Nymphaea (Nymphaeaceae) in Australasia. Telopea 5: 703706.

Jacobs SWL (2007) Nymphaea subg. Confluentes. P. 458 in Wilson AJG (ed.) Flora of Australia, vol. 2. (CSIRO and Australian Biological Resources Study: Melbourne)

Jacobs SWL \& Hellquist CB (2006) Three new species of Nymphaea (Nymphaeaceae) in Australia. Telopea 11: 155-160.

Jacobs SWL \& Hellquist CB (2011) New species, possible hybrids and intergrades in Australian Nymphaea (Nymphaeaceae) with a key to all species. Telopea 13: 233-243.

Jacobs SWL \& Porter CL (2007) Nymphaeaceae. Pp. 259-275 in Wilson AJG (ed.) Flora of Australia, vol. 2. (CSIRO and Australian Biological Resources Study: Melbourne)

Kolaczkowski B \& Thornton JW (2009) Long-Branch attraction bias and inconsistency in Bayesian Phylogenetics. PloS One 4: e7891.

Landon K, Edwards RA \& Nozaic PI (2006) A new species of waterlily (Nymphaea minuta, Nymphaeaceae) from Madagascar. Sida 22: 887-893.

Linder HP, Hardy CR \& Rutschmann F (2005) Taxon sampling effects in molecular lock dating: an example from the African Restionaceae. Molecular Phylogenetics and Evolution 35: 569-582.

Löhne C \& Borsch T (2005) Molecular evolution and phylogenetic utility of the petD group II intron: A case study in basal angiosperms. Molecular Biology and Evolution 22: 317-332.

Löhne C, Borsch T \& Wiersema JH (2007) Phylogenetic analysis of Nymphaeales using fastevolving and non-coding chloroplast markers. Botanical Journal of the Linnean Society 154: 141-163.

Löhne C, Borsch T, Jacobs SWL, Hellquist CB \& Wiersema JH (2008a) Nuclear and plastid DNA sequences reveal complex reticulate patterns in Australian water-lilies (Nymphaea subgenus Anecphya, Nymphaeaceae). Australian Systematic Botany 21: 229-250.

Löhne C, Yoo M-J, Borsch T, Wiersema JW, Wilde V, Bell CD, Barthlott W, Soltis DE \& Soltis PS (2008b) Biogeography of Nymphaeales: Extant patterns and historical events. Taxon 57: 1123-1146.

Löhne C, Wiersema JH \& Borsch T (2009) The unusual Ondinea, actually just another Australian water-lily of Nymphaea subg. Anecphya (Nymphaeaceae). Willdenowia 39: 55-58.

McLoughlin S (2001) The breakup history of Gondwana and its impact on pre-Cenozoic floristic provincialism. Australian Journal of Botany 49: 271-300.

Mitra RL \& Subramanyam K (1982) Is Nymphaea rubra Roxb. ex Andrews an apomict? Bulletin of the Botanical Survey of India 24: 83-86. 
Morley RJ (2003) Interplate dispersal paths for megathermal angiosperms. Perspectives in Plant Ecology, Evolution and Systematics 6: 5-20.

Müller K (2004) PRAP - computation of Bremer support for large data sets. Molecular Phylogenetics and Evolution 31, 780-782.

Müller K (2005) SeqState: Primer design and sequence statistics for phylogenetic DNA datasets. Applied Bioinformatics 4: 65-69.

Müller J, Müller KF, Neinhuis C \& Quandt D (2007) PhyDE - Phylogenetic Data Editor. Programme distributed by the author. http://www.phyde.de.

Müllner AN, Savolainen V, Samuel R \& Chase MW (2006) The mahogany family « out-ofAfrica $»$ : Divergence time estimation, global biogeographic patterns inferred from plastid $r b c L$ DNA sequences, extant, and fossil distribution of diversity. Molecular Phylogenetics and Evolution 40: 236-250.

Nylander JAA (2004) MrModeltest 2.2. Programme distributed by the author. Evolutionary Biology Centre, Uppsala University.

Renner SS (2004) Plant dispersal across the tropical Atlantic by wind and sea currents. International Journal of Plant Sciences 165: S23-S33.

Renner SS, Clausing G \& Meyer K (2001) Historical biogeography of Melastomataceae: the roles of Tertiary migration and long-distance dispersal. American Journal of Botany 88: 1290-1300.

Ronquist F \& Huelsenbeck JP (2003) MRBAYES 3: Bayesian phylogenetic inference under mixed models. Bioinformatics 19: 1572-1574.

Sanmartín I, Anderson CL, Alarcon M, Ronquist F \& Aldasoro JJ (2010) Bayesian island biogeography in a continental setting: the Rand Flora case. Biology Letters 6: 703-707.

Sauquet H, Doyle JA, Scharaschkin T, Borsch T, Hilu KW, Chatrou LW \& Le Thomas A (2003) Phylogenetic analysis of Magnoliales and Myristicaceae based on multiple data sets: implications for character evolution. Botanical Journal of the Linnean Society 142: 125-186.

Simmons MP \& Ochoterena H (2000) Gaps as characters in sequence-based phylogenetic analyses. Systematic Biology 49: 369-381.

Simmons MP, Pickett KM \& Miya M (2004) How meaningful are Bayesian support values? Molecular Biology and Evolution 21: 188-199.

Swofford DL (2002) PAUP*. Phylogenetic analysis using parsimony ( ${ }^{*}$ and other methods). Version 4.0b10., Sinauer Associates, Sunderland, Massachusetts.

Suzuki Y, Glazko GV \& Nei M (2002) Overcredibility of molecular phylogenies obtained by Bayesian phylogenetics. Proceedings of the National Academy of Sciences of the United States of America 99: 16138-16143.

Taberlet P, Gielly L, Pautou G \& Bouvet J (1991) Universal primers for amplification of 3 noncoding regions of chloroplast DNA. Plant Molecular Biology 17: 1105-1109.

Tiffney BH \& Manchester SR (2001) The use of geological and paleontological evidence in evaluating plant phylogeographic hypotheses in the northern hemisphere Tertiary. International Journal of Plant Sciences 162: S3-S17.

USDA, ARS, National Genetic Resources Program. Germplasm Resources Information Network - (GRIN) [On-line Database]. National Germplasm Resources Laboratory, Beltsville, Maryland. (http://www.ars-grin.gov/cgi-bin/npgs/html/queries.pl) (Accessed 06 June 2010)

Venu P, Rajakumar TJS \& Daniel P (2003) On the identity of and sterility in Nymphaea rubra Roxb. ex Andrews (Nymphaeaceae). Rheedea 13: 29-34.

Volkova PA, Trávníček P \& Brochmann C (2010) Evolutionary dynamics across discontinuous freshwater systems: Rapid expansions and repeated allopolyploid origins in Palearctic white water-lilies (Nymphaea). Taxon 59: 483-494.

White TJ, Bruns T, Lee S \& Taylor J (1990) Amplification and direct sequencing of fungal ribosomal RNA genes for phylogenetics. Pp. 315-322 in Innis DGM, Sninsky J \& White T (eds) PCR protocols: a guide to methods and applications. (Academic Press: San Diego, CA)

Wiersema JH (1987) A monograph of Nymphaea subgenus Hydrocallis (Nymphaeaceae). Systematic Botany Monographs 16: 1-112.

Wiersema JH, Novelo AR \& Bonilla-Barbosa JR (2008) Taxonomy and typification of Nymphaea ampla (Salisb.) DC. sensu lato (Nymphaeaceae). Taxon 57: 967-974. 
Woods K, Hilu KW, Borsch T \& Wiersema JH (2005) Pattern of variation and systematics of Nymphaea odorata: II. Sequence information from ITS and trnL-trnF. Systematic Botany 30: 481-493.

Yoo MJ, Bell CD, Soltis PS \& Soltis DE (2005) Divergence times and historical biogeography of Nymphaeales. Systematic Botany 30: 693-704.

Manuscript received 08 August 2010, accepted 15 November 2010 


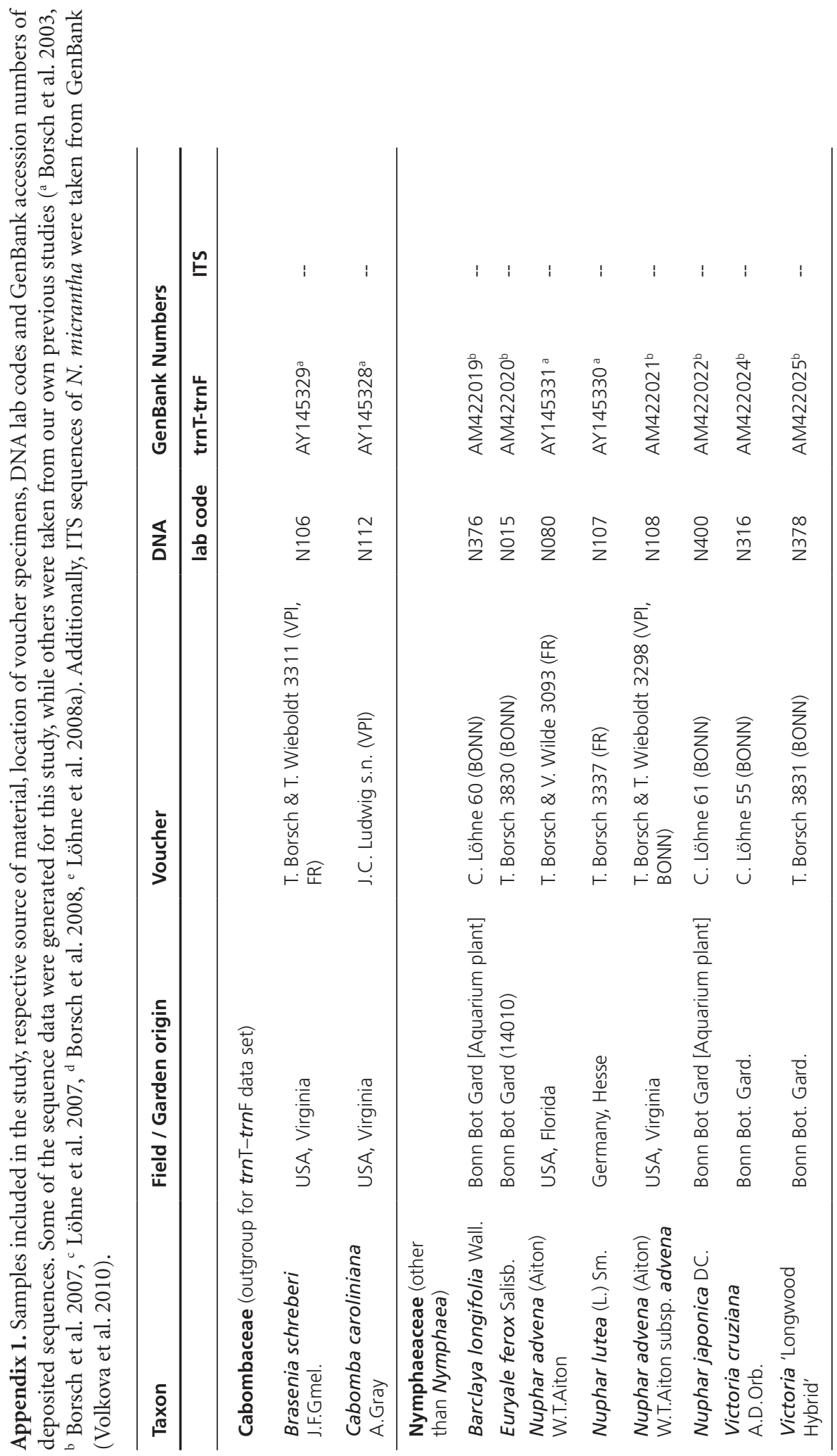




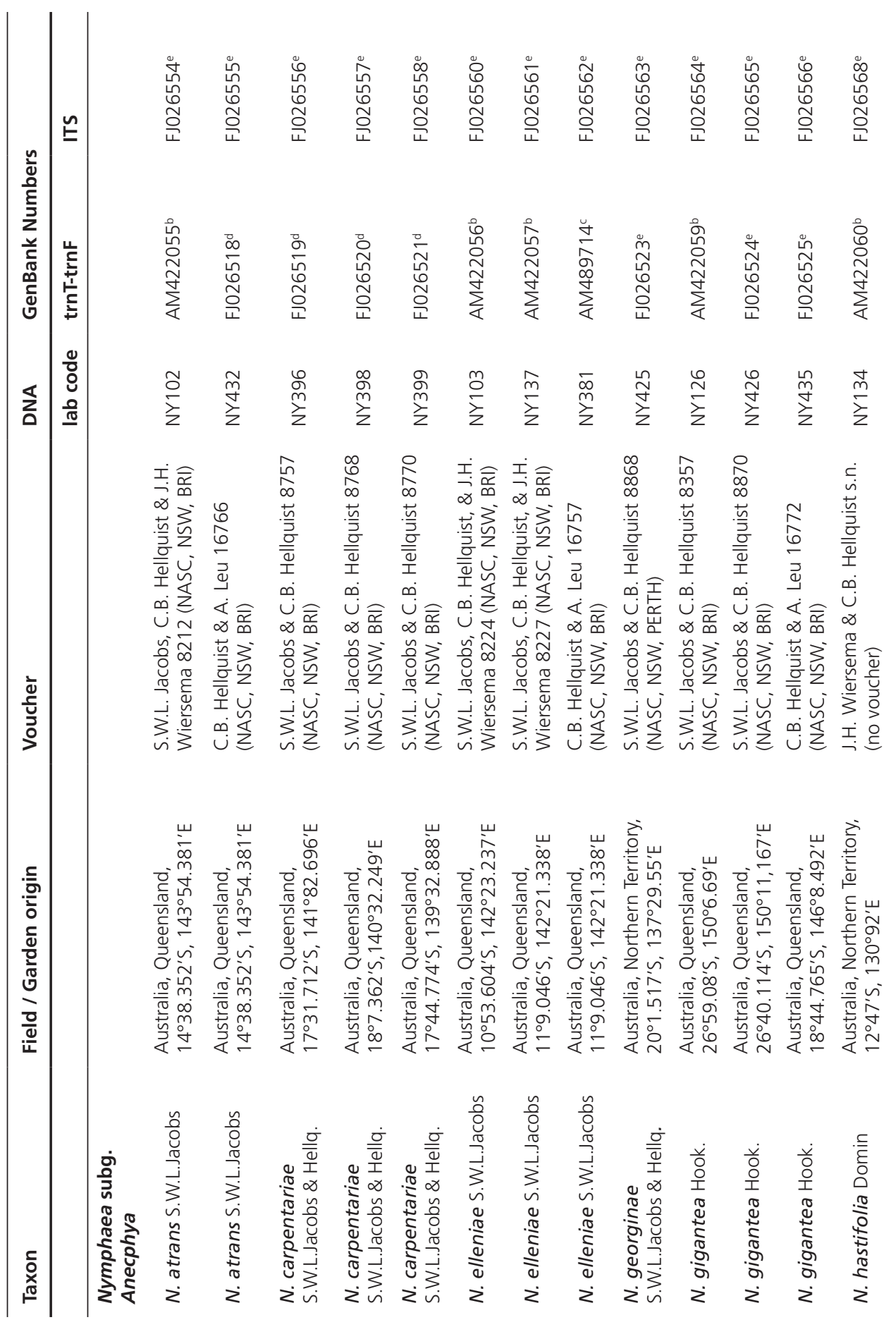




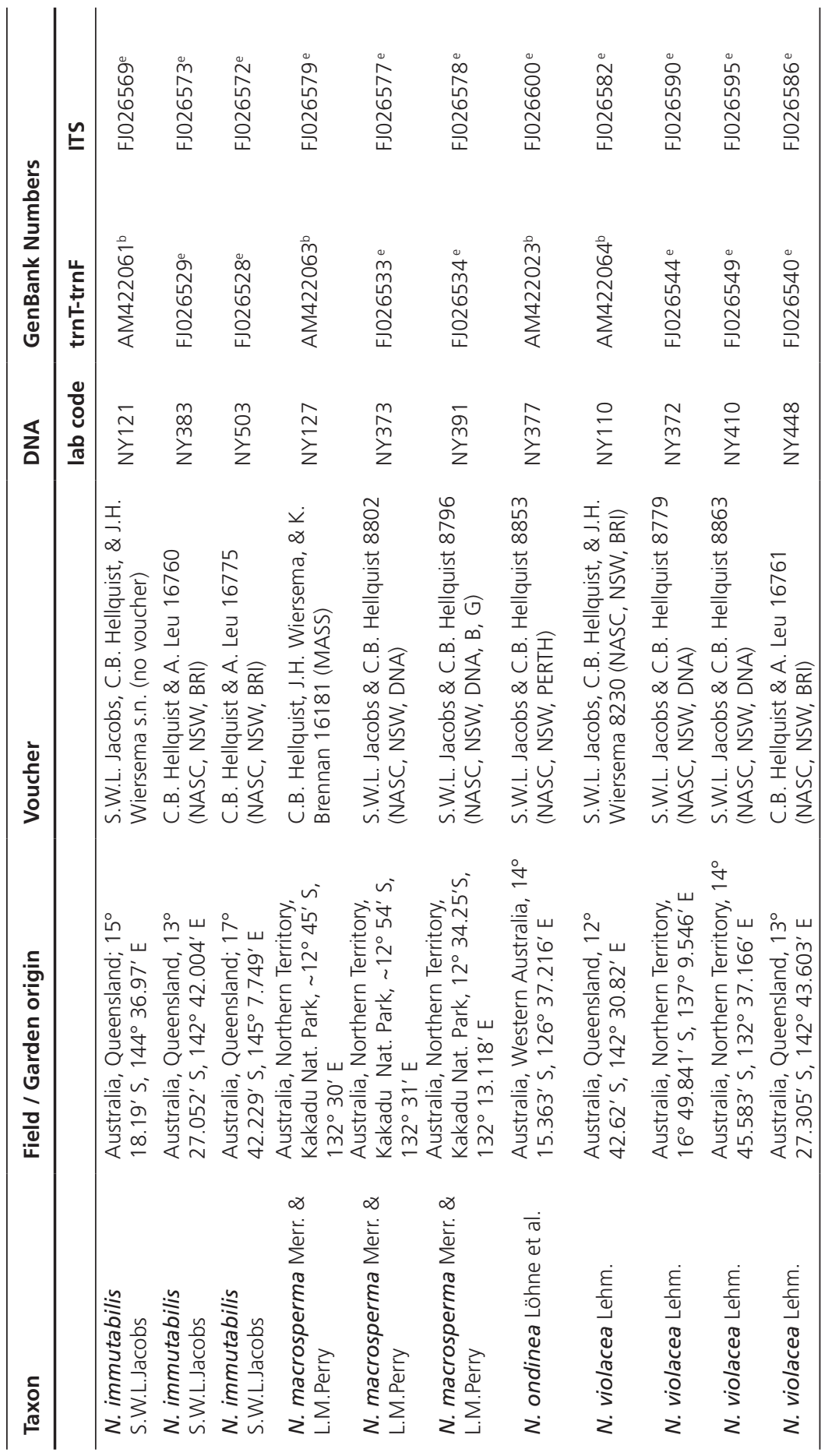




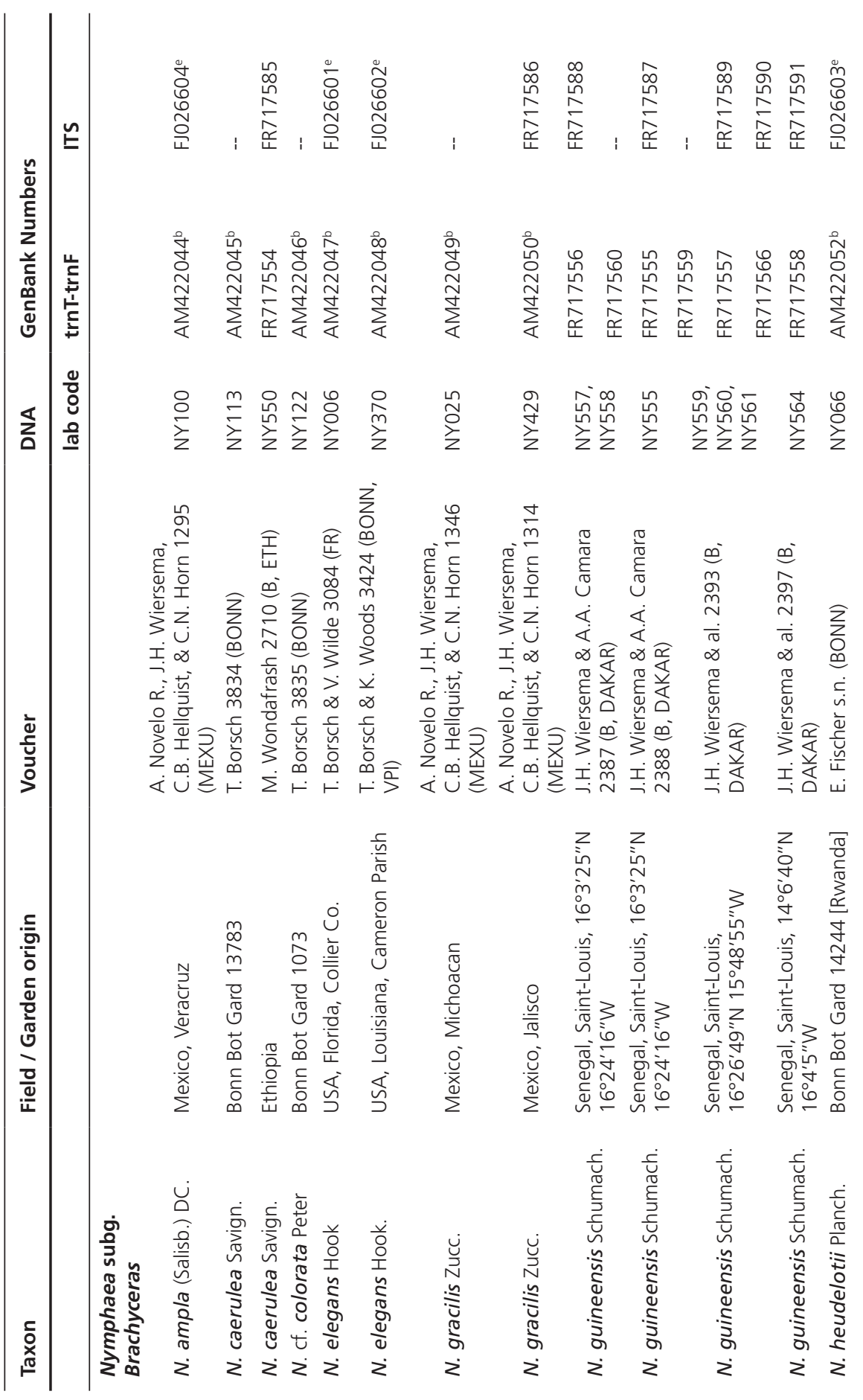




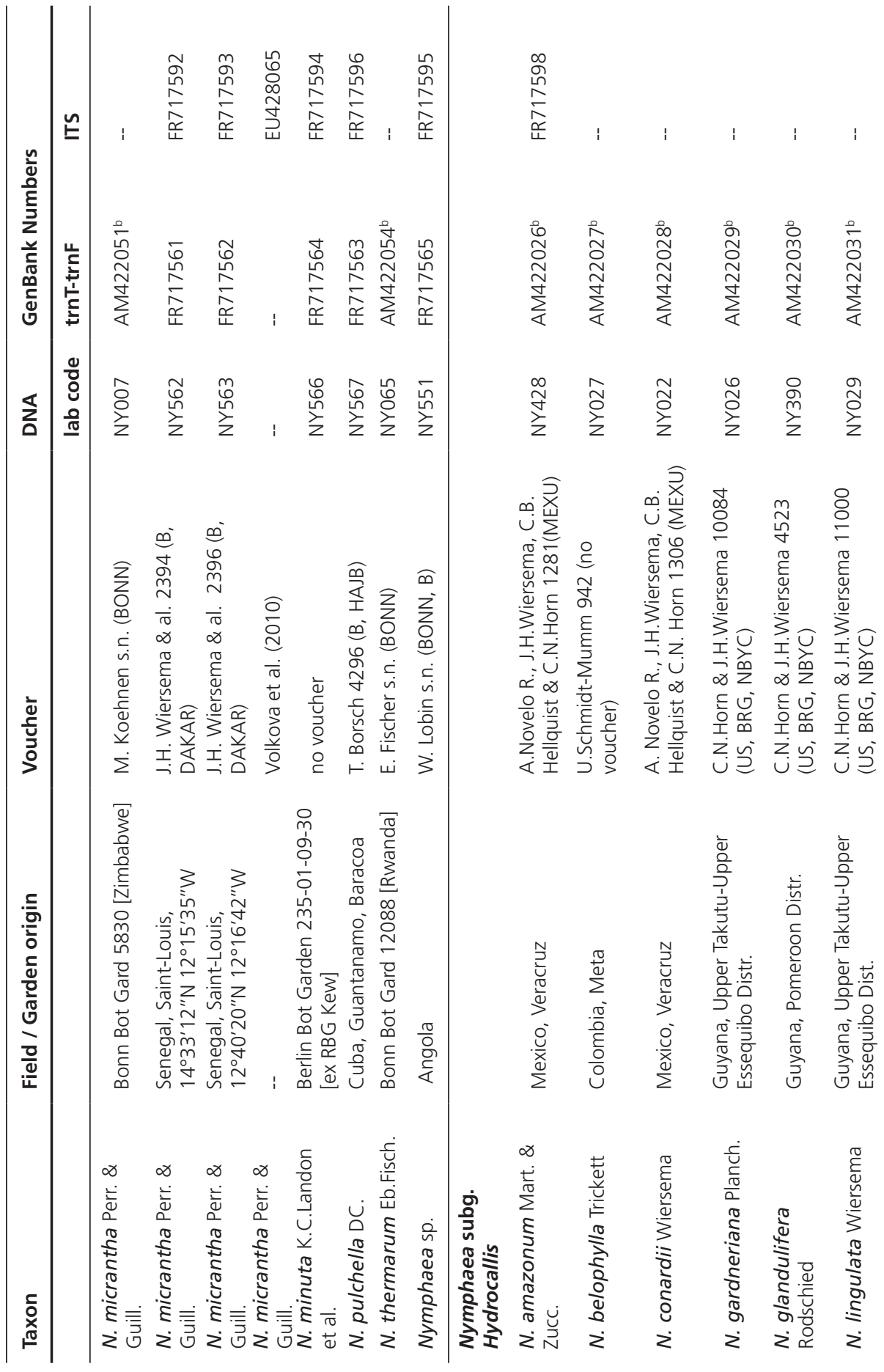




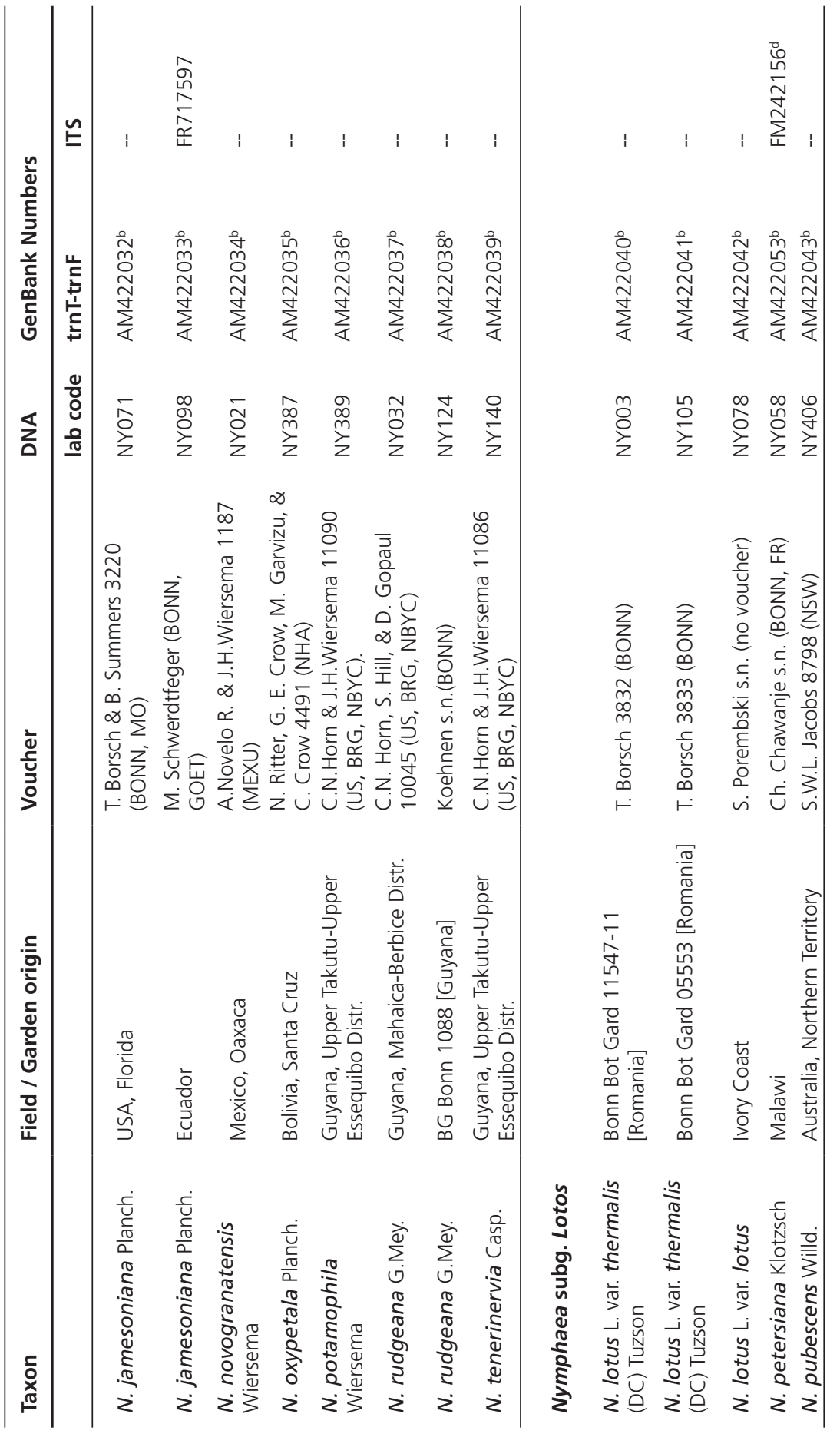




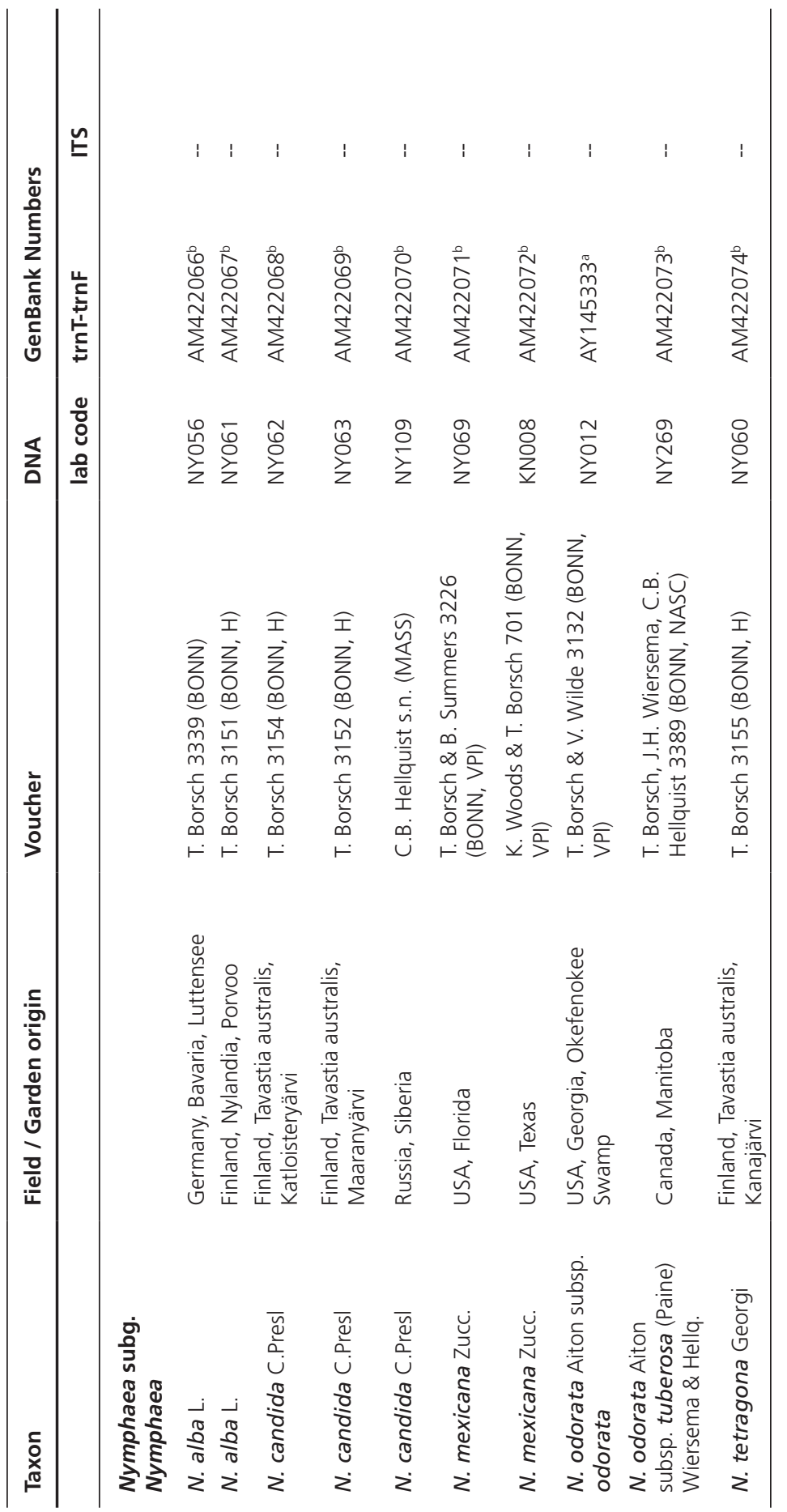

